\title{
Diversity and associations between Drosophilidae (Diptera) species and Basidiomycetes in a Neotropical forest
}

\author{
FELIPE B. VALER ${ }^{1}$, EDUARDO BERNARDI ${ }^{2}$, MAYARA F. MENDES ${ }^{3}$, \\ MONICA L. BLAUTH ${ }^{3}$ and MARCO S. GOTTSCHALK ${ }^{3}$

\begin{abstract}
${ }^{1}$ Departamento de Biologia Celular e Molecular e Bioagentes Patogênicos, Faculdade de Medicina de Ribeirão Preto, Universidade de São Paulo (USP), Avenida Bandeirantes, 3900, 14049-900 Ribeirão Preto, SP, Brasil

${ }^{2}$ Departamento de Microbiologia e Parasitologia, Instituto de Biologia, Campus Capão do Leão, Universidade Federal de Pelotas (UFPel), Caixa Postal 354, 96010-000 Pelotas, RS, Brasil

${ }^{3}$ Departamento de Ecologia, Zoologia e Genética, Instituto de Biologia, Campus Capão do Leão, Universidade Federal de Pelotas (UFPel), Caixa Postal 354, 96010-000 Pelotas, RS, Brasil
\end{abstract}

Manuscript received on May 21, 2015; accepted for publication on July 27, 2015

\begin{abstract}
Drosophilidae is one of the most representative families of insects that occurs in fungal fruiting bodies of Basidiomycetes; however, the diversity and community structure of mycophagous Drosophilidae in the Neotropical region is poorly known. The aims of the present study were to describe the diversity of mycophagous Drosophilidae and to investigate its colonization of fungal hosts in a forest of southern Brazil. From 120 fungal samples (patches of mushrooms) of 17 Basidiomycetes genera, flies were recorded emerging from 70 samples and collected in adult stages of 25 fungal samples, for a total of 4897 drosophilids belonging to 31 species and 5 genera. Drosophila Fallén was the most species-rich genus, whereas Hirtodrosophila Duda was the dominant genus. Studies performed in the Holarctic region indicate that mycophagous drosophilid have generalist habits; however, our results showed that most drosophilids use fewer than two fungal hosts, and most species of Hirtodrosophila and Leucophenga were restricted to abundant fungal species, suggesting a specialization for these resources. The most specialized fauna emerged from Auricularia, which was the most frequent fungal genus in our collection, and this result supports the assumption that specialization depends on the availability of fungal resources over time.
\end{abstract}

Key words: generalist species, mycophagy, mushrooms, Pampa biome, specialist species, trophic niche.

\section{INTRODUCTION}

A variety of insects colonize fruiting bodies of Basidiomycetes fungi; however, Drosophilidae is usually the most representative family because the flies use these bodies for feeding, mating and breeding sites (Bunyard 2003, Courtney et al.

Correspondence to: Marco Silva Gottschalk

E-mail: marco.gottschalk@yahoo.com
1990, Shorrocks and Charlesworth 1980, Toda et al. 1999). Mycophagy in Drosophilidae is most likely derived from detritivorous feeding habits and may have arisen several times during their evolution (Throckmorton 1975). This habit is possibly synapomorphic in the genera Hirtodrosophila Duda, Mycodrosophila Oldenberg and Zygothrica Wiedemann (Grimaldi 1987) and 
homoplasic in Drosophila Fallén, Leucophenga Mik and Scaptomyza Hardy (Courtney et al. 1990). Mycophagy was also suggested in the genera Paraliodrosophila Duda and Paramycodrosophila Duda (Vilela and Bächli 2007), which are closely related to Hirtodrosophila, Mycodrosophila and Zygothrica (Grimaldi 1990).

In certain species of Drosophilidae, fungal fruiting bodies are the only resource required throughout the life cycle, and such behavior is observed in Hirtodrosophila (except for rare instances, see Grimaldi 1987) and Mycodrosophila species, which are primarily mycophagous because they depend on the fungi for breeding and feeding sites (Courtney et al. 1990). In other drosophilids, mycophagy is more labile, and fungi represent only a fraction of the resources used. Such behavior can be observed in species of Zygothrica, which can be found in fungi and flowers, or Drosophila, which may use a wide range of hosts, such as cacti, flowers, sap, fruits and fungi (Carson 1971, Markow and O'Grady 2008).

Despite a broad larval niche, a number of Drosophila species were dominant in the fungi collected from the Holarctic region, where most of the ecological studies of mycophagous drosophilids have been conducted (Lacy 1984, Takahashi et al. 2005, Wertheim et al. 2000). The main Drosophila species groups that emerged from this resource were pinicola, quinaria, testacea and tripunctata, which all belong to the immigrans-tripunctata radiation (Markow and O'Grady 2006, Remsen and O'Grady 2002). However, in certain mycophagous communities, other genera stand out in species richness and abundance, such as Hirtodrosophila, Leucophenga and Mycodrosophila (Bunyard 2003, Toda et al. 1999, Tuno 1999). For instance, Leucophenga was the dominant genus and Hirtodrosophila was the most species-rich genus among the flies emerging from fungi in a largescale field survey in Australia (van Klinken and Walter 2001).
In the Neotropical region, few studies have addressed mycophagous Drosophilidae. From the 1940s to 1960 s, taxonomic studies described a number of mycophagous Hirtodrosophila and Zygothrica species but did not investigate their ecology (Burla 1956, Cordeiro 1952, FrotaPessoa 1945, 1951, Mourão et al. 1965). Despite the frequency and diversity of Drosophilidae, few ecological studies have reported their feeding, mating or breeding habits on mushrooms (Grimaldi 1987, Heed 1957). In Brazil, such collections were conducted in only two biomes: the Atlantic Rainforest biome (Gottschalk et al. 2009, Val and Kaneshiro 1988) and the Cerrado biome (Roque et al. 2006, Roque and Tidon 2008). These studies expanded the knowledge of drosophilid species with mycophagous habits.

Although studies of Holarctic fauna have provided important contributions to our understanding of the ecology and evolution of mycophagous drosophilids, the characteristics of fauna in this region may differ from those of the Neotropical region as suggested by Courtney et al. (1990). Thus, the aim of this study was to describe the diversity of the drosophilid assemblage associated with fungal species of Basidiomycetes in a forest area of the Pampa biome located in southern Brazil.

\section{MATERIALS AND METHODS}

\section{STUDY AREA}

We conducted this study in a restinga forest located in a grassland formation of 23 ha belonging to the Federal Conservation Unit Horto Botânico Irmão Teodoro Luís (HBITL, 31 ${ }^{\circ} 48^{\prime} 54$ '” $\mathrm{S}, 52^{\circ} 25^{\prime} 48^{\prime \prime} \mathrm{W}$ ), Rio Grande do Sul, Brazil (Fig. 1). HBITL is located in the Pampa biome and surrounded by wetlands, grassland areas and semideciduous forest remnants (Wolff et al. 2008).

The forest structure of HBITL shows at least three vegetation strata: arboreal, shrub and 


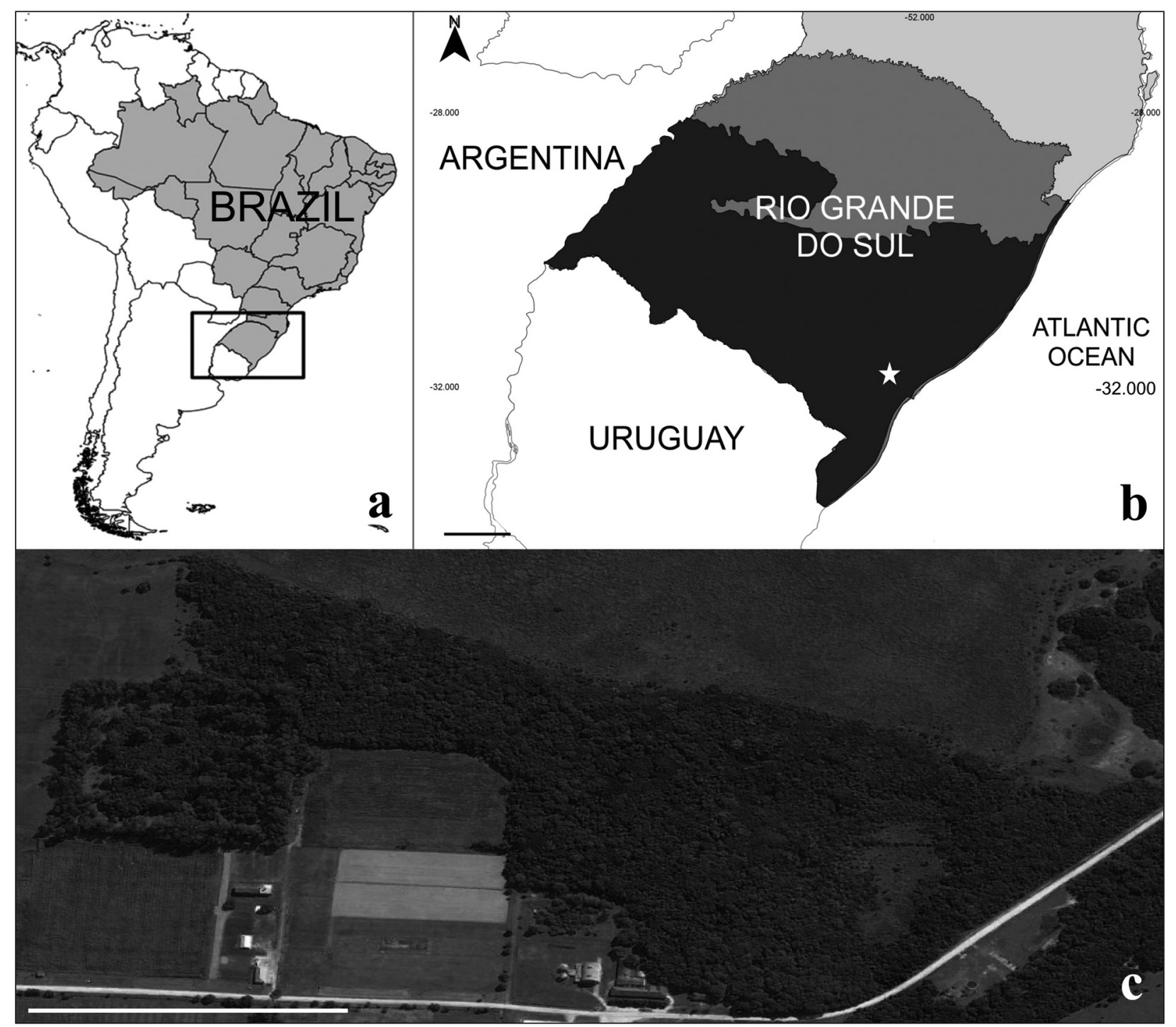

Figure 1 - Location of the Horto Botânico Irmão Teodoro Luís (HBITL). a. Map of South America with Brazil in gray and state of Rio Grande do Sul highlighted. b. Map of Rio Grande do Sul indicating the location of HBITL with a star, Pampa biome in black and Atlantic Rainforest biome in dark gray. c. Satellite photograph of the surveyed restinga forest area of HBITL (Source: Google Earth $^{\circledR}$ ). Scale bars: $100 \mathrm{~km}$ in $\mathbf{b} ; 300 \mathrm{~m}$ in $\mathbf{c}$.

herbaceous. Ficus luschnathiana (Miq.) Miq. is a frequent canopy tree, but other native species also occur, such as Trichilia claussenii C.DC., Cordia americana (L.) Gottshling \& J.E.Mill., Sideroxylon obtusifolium (Roem. \& Schult.) T.D. Penn., Nectandra megapotamica (Spreng.) Mez, Cupania vernalis Cambess, Luehea divaricata Mart. \& Zucc. and Sorocea bonplandii (Baill.) W.C. Burger, Lanjouw \& Boer. The exotic species Asparagus setaceus (Kunth) Jessop is widely distributed from the forest edge of the HBITL, and a large number of trees at different ages provide continuous contributions to the abundance of coarse woody debris (J.N. Schlee Jr, unpublished data).

According to the Köppen classification system, the climate is Cfa (Kottek et al. 2006). Meteorological measurements performed between 1971 and 2000 reveal that the average annual temperature is $17.8^{\circ} \mathrm{C}$ and maximum and minimum monthly mean temperatures are $28.2^{\circ} \mathrm{C}$ and $8.6^{\circ} \mathrm{C}$, 
respectively (Agrometeorological Station of Pelotas 2014). The rainfall is $1367 \mathrm{~mm} /$ year, there are approximately 120 rainy days, and the annual relative humidity is $80 \%$.

\section{DATA COLLECTION}

We searched for Basidiomycetes fungi along a 200 $\mathrm{m}$ trail, and we extended our search $10 \mathrm{~m}$ on either side of the trail. Fruiting bodies were found on the roots of plants, in leaf litter or on decaying wood. The collections were performed monthly between February and May 2011 and between February and June 2013, and each collection was conducted over a period of three hours in the morning. The sampling units of this study are patches of fungal bodies. We also captured adults on fruiting bodies with a net or entomological aspirator and fixed them in $70 \%$ ethanol in the field.

All of the fruiting bodies found in the field were collected, and when a large number of mushrooms was observed in the same location, only a fraction were collected. The collected fruiting bodies were transported in plastic bags to the laboratory, where they were then weighed to quantify the fungal mass, stored in glass vials with autoclaved sand and covered with synthetic mesh. To prevent dehydration, distilled water was added to the sand. Samples were maintained at $25 \pm 1{ }^{\circ} \mathrm{C}$ for four or five weeks, and during this period, the emergent insects were aspirated daily and fixed in $70 \%$ ethanol.

\section{IDENTIFICATION OF BIOLOGICAL MATERIAL}

We identified drosophilid males based on their external morphology and genitalia according to Frota-Pessoa (1945), Burla (1956), Wheeler and Takada (1971), Grimaldi $(1987,1990)$ and Vilela and Bächli (1990, 2004, 2007). We prepared the genitalia in accordance with Wheeler and Kambysellis (1966) and using Kaneshiro's (1969) modifications. The females were identified based on the external morphology to the lowest taxonomic level possible. For analyses, we considered the abundance of females of cryptic species to be proportional to the number of emerged males from the same sample.

The fungus genera and/or species were identified via photos of the fruiting bodies taken in the field according to Lincoff $(1981,2010)$, Putzke and Putzke (1998), Polese (2005) and Laessoe and Lincoff (2010). Because of the advanced decay stage of certain fruiting bodies, we could not identify a number of samples, which were excluded from the analyses conducted at the species level.

\section{ASSEMBLAGE CHARACTERIZATION}

We assessed species dominance within the assemblage via a Whittaker plot that considered the relative abundance of species ( $p i$, ratio between the absolute abundance of species $i$ and total abundance) (Krebs 1999). Sampling adequacy was evaluated using emergence data from Basidiomycetes samples in a randomized species accumulation curve. The bootstrap method was used to support the sampling sufficiency (Epps and Arnold 2010, Smith and van Belle 1984) and performed with EstimateS v. 8.2.0 software with 500 randomizations (Colwell 2006).

The use of each fungal species by drosophilid species was evaluated according to the ratio between the number of colonized samples and total number of samples of each fungal species. To assess the species' temporality, the relative frequency of fungal species was calculated as the ratio between the number of collections in which the species were observed and total number of collections (eight collections).

We conducted Spearman's correlations between the total number of samples, total mass of fungal samples, relative frequency of each fungal species and total abundance and species richness of emerged drosophilid species. 
To visualize the association between host fungal species and drosophilid species, we performed a correspondence analysis (CA) in the program Past v.2.17b (Hammer et al. 2001). The fungal species were considered as the independent variable, and drosophilid species abundance (with Log transformation) was considered as the dependent variable. To avoid the inclusion of subsampled species of drosophilid and fungus, three criteria were adopted for inclusion in the CA: (1) drosophilid species must have an absolute abundance $\geq 10$ individuals; (2) drosophilid species must have been collected in at least three samples; and (3) fungal samples had to be determined to the species level. To test the significance of the groups obtained with the CA, an analysis of similarity (ANOSIM) using the Bray-Curtis index was conducted using the program Past v.2.17b. The Bonferroni correction for multiple comparisons was performed to adjust the significance.

\section{RESULTS}

We collected 4897 drosophilids in 5 genera and 31 species. Of these, 4620 individuals in 26 species emerged from 70 samples, and 277 adult flies in 17 species were collected on 25 samples (Tables I and II, respectively). Although the drosophilid assemblage was not sampled to saturation, our sampling approach was sufficiency (Fig. 2) because we recovered $90 \%$ of the 29 drosophilid species predicted by the bootstrap analysis.

To characterize our collection, the number of samples, mass ( $\mathrm{g}$ ) and relative frequency for each collected fungal species are shown in Table I. The number of fungus samples was positive correlated with the total abundance ( $\mathrm{rs}=0.683 ; \mathrm{p}=0.0003$; $\mathrm{df}=22$ ) and species richness of the emerged flies ( $r s=0.719 ; \mathrm{p}=0.0001 ; \mathrm{df}=22$ ). The abundance of emerged flies was also correlated with the total mass of fungal samples ( $\mathrm{rs}=0.497 ; \mathrm{p}=0.015$; $\mathrm{df}=22)$, although species richness was not ( $\mathrm{rs}=$
$0.349 ; \mathrm{p}=0.102 ; \mathrm{df}=22$ ). In addition, the relative frequency of fungal species was positive correlated with drosophilid abundance $(\mathrm{rs}=0.702 ; \mathrm{p}=$ $0.0002 ; \mathrm{df}=22)$ and species richness $(\mathrm{rs}=0.744 ; \mathrm{p}$ $=0.00005 ; \mathrm{df}=22$ ).

Out of 120 Basidiomycetes samples identified at the genus level, 57 were positive for drosophilid emergence or adult collection events, whereas 63 were negative (see Appendix S1 in Supporting Information - Supplementary Material). Positive samples of Coprinus Persoon, Lycoperdon Persoon, Cantharellus Jussieu, Cortinarius (Persoon) Gray, Panus Fries and Clitocybe (Fries) Staude were not observed, although Lycoperdon was sampled on five occasions. For most of the observed fungal species, less than $50 \%$ were colonized by drosophilids, and Agaricus Linnaeus, Auricularia Bulliard ex Jussieu, Polyporus P. Micheli ex Adanson and Melanoleuca Patouillard were the only genera that had colonized more than $50 \%$ of the samples. Of these last four genera, only Melanoleuca was sampled in a single collection, whereas Agaricus and Auricularia were the second-and third-most sampled genera (19 and 18 samples, respectively), indicating that they are important resources for the drosophilid assemblage. Furthermore, considering the relative frequency of fungal species as a measure of temporal availability, Auricularia auricula-judae (Bulliard) J. Schröter was the most common species at a relative frequency of 0.75 , and it was followed by A. polytricha (Montagne) Saccardo and Polyporus sp.1, which both had a relative frequency of 0.40 .

The dominant drosophilid species in our samples (pi $\geq 0.10$ ) were Hirtodrosophila morgani aff., which had the highest relative abundance, $H$. mendeli (Mourão, Gallo and Bicudo), Zygothrica bilineata (Williston) and H. levigata (Burla) (Fig. $3)$. The intermediary species $(0.10>$ pi $\geq 0.01)$ were Z. ptilialis Burla, H. morgani (Mourão, Gallo and Bicudo), Leucophenga sp.L002, Drosophila paraguayensis Duda and Leucophenga sp.L001. 
FELIPE B. VALER et al.

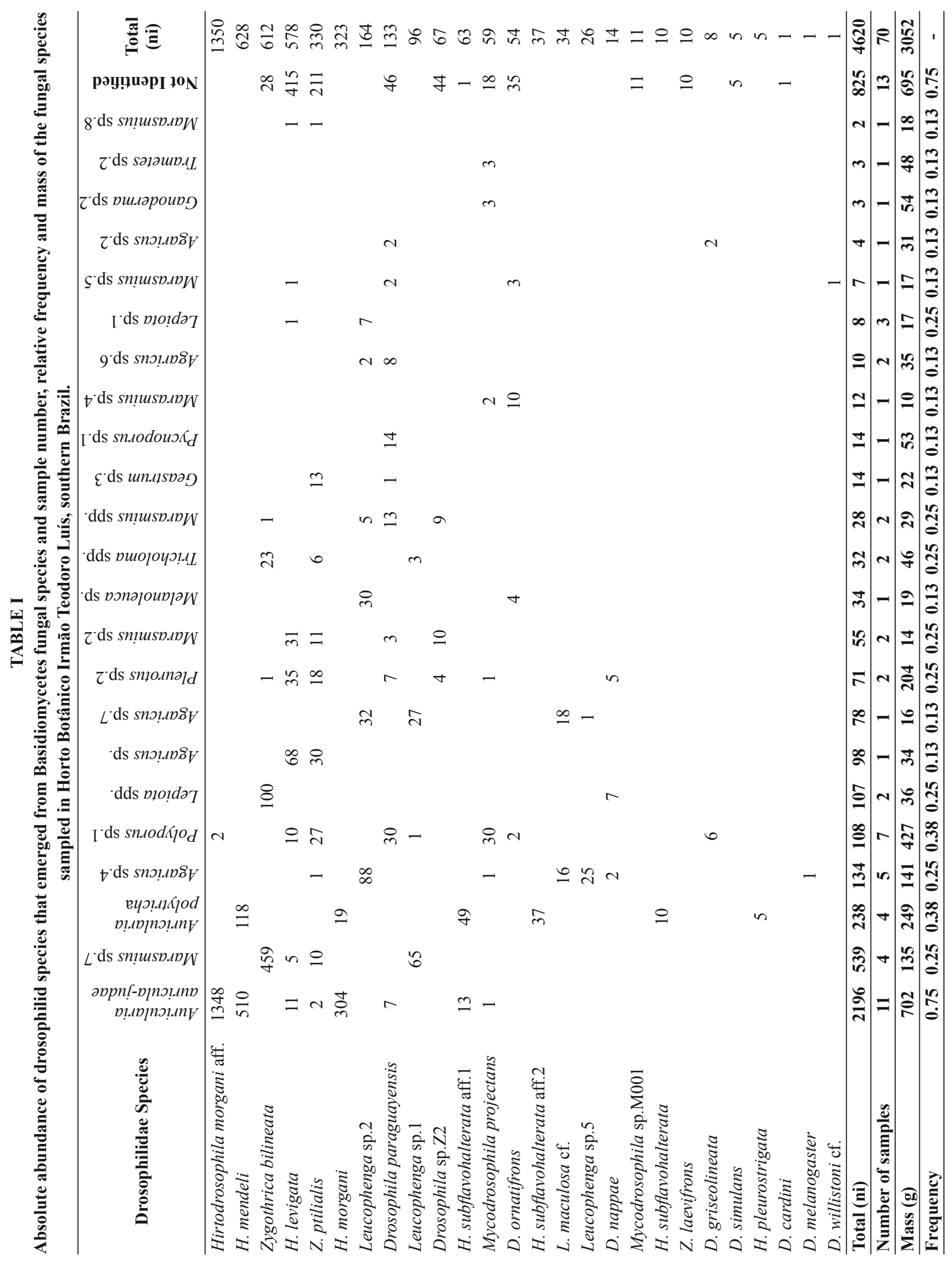


TABLE II

Absolute abundance of drosophilid species sampled as adults on Basidiomycetes fungal species in Horto Botânico Irmão Teodoro Luís, southern Brazil.

\begin{tabular}{|c|c|c|c|c|c|c|c|c|c|c|c|}
\hline Drosophilidae Species & 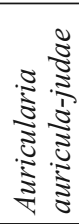 & 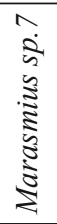 & 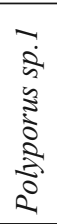 & 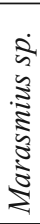 & 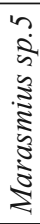 & 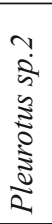 & 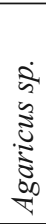 & 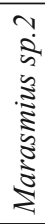 & 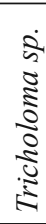 & 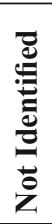 & $\begin{array}{l}\text { Total } \\
\text { (ni) }\end{array}$ \\
\hline Zygothrica ptilialis & 50 & 13 & 8 & & 3 & 3 & 2 & & & 6 & 85 \\
\hline Zygothrica sp.Z002 & 36 & & & & & & & & & & 36 \\
\hline Hirtodrosophila levigata & 14 & 1 & 5 & & & & & 1 & & 7 & 28 \\
\hline H. morgani aff. & 24 & & & & & & & & & & 24 \\
\hline H. mendeli & 19 & & 3 & & & & & & & & 22 \\
\hline Z. bilineata & & 16 & & & & & & & 1 & 4 & 21 \\
\hline H. morgani & 18 & & 2 & & & & & & & & 20 \\
\hline Drosophila paraguayensis & & & & 3 & & & & & & 16 & 19 \\
\hline D. nappae & & & 5 & & & & & & & & 5 \\
\hline Z. dispar & & 4 & & & & & & & & & 4 \\
\hline Z. prodispar & & 4 & & & & & & & & & 4 \\
\hline D. willistoni $c f$. & & & 3 & & & & & & & & 3 \\
\hline Z. vittimaculosa & 2 & & & & & & & & & & 2 \\
\hline Drosophila sp.Z2 & & & & & & & & 1 & & & 1 \\
\hline H. subflavohalterata aff.1 & 1 & & & & & & & & & & 1 \\
\hline Mycodrosophila projectans & & & & & & & & & & 1 & 1 \\
\hline Z. orbitalis & 1 & & & & & & & & & & 1 \\
\hline Total (ni) & 165 & 38 & 26 & 3 & 3 & 3 & 2 & 2 & 1 & 34 & 277 \\
\hline Number of samples & 6 & 2 & 5 & 1 & 1 & 1 & 1 & 1 & 1 & 6 & 25 \\
\hline
\end{tabular}

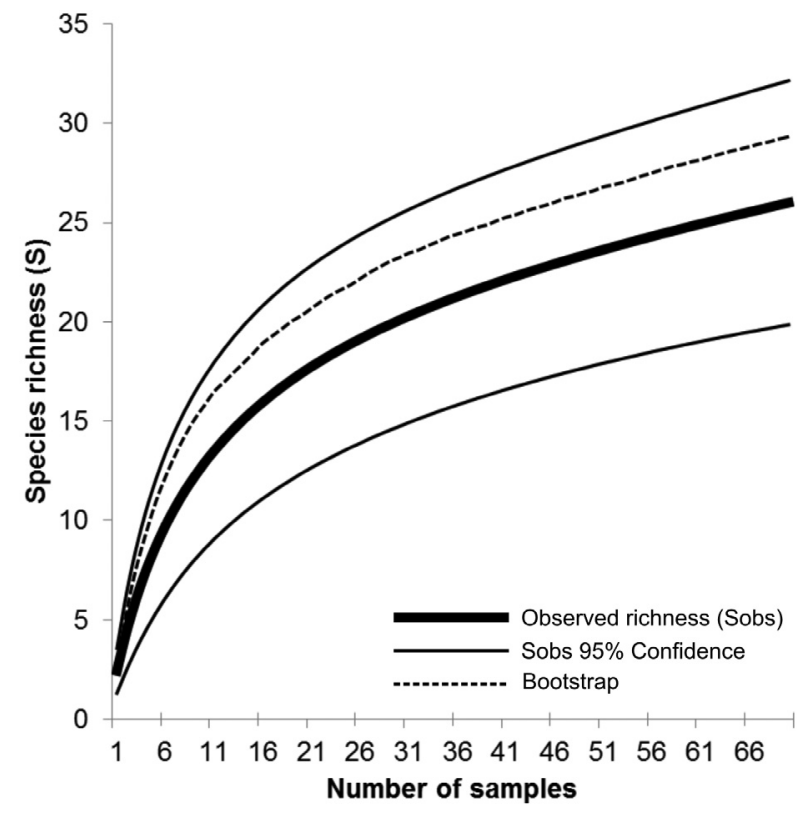

Figure 2 - Species accumulation curve for the drosophilid assemblage and species richness estimation by the bootstrap method.
These nine species accounted for approximately $90 \%$ of emerging individuals. The remaining 17 species were rare in our sample $(\mathrm{pi}<0.01)$.

Fig. 4 shows the number of fungal species from which the drosophilid species emerged, and it provides an overview of the resource range that these species can use, suggesting varying degrees of specialization. The drosophilid species that use other resources in addition fungi, such as $D$. paraguayensis and Z. ptilialis (Garcia et al. 2012), utilize a larger number of fungal species for larva rearing. Similarly, predominantly mycophagous species, such as H. levigata and Mycodrosophila projectans (Sturtevant) (Courtney et al. 1990), were also common and found in a large number of fungal host species. Five species of Zygothrica [Z. dispar (Wiedemann), Z. orbitalis (Sturtevant), Z. prodispar Duda, Z. vittimaculosa Burla and 


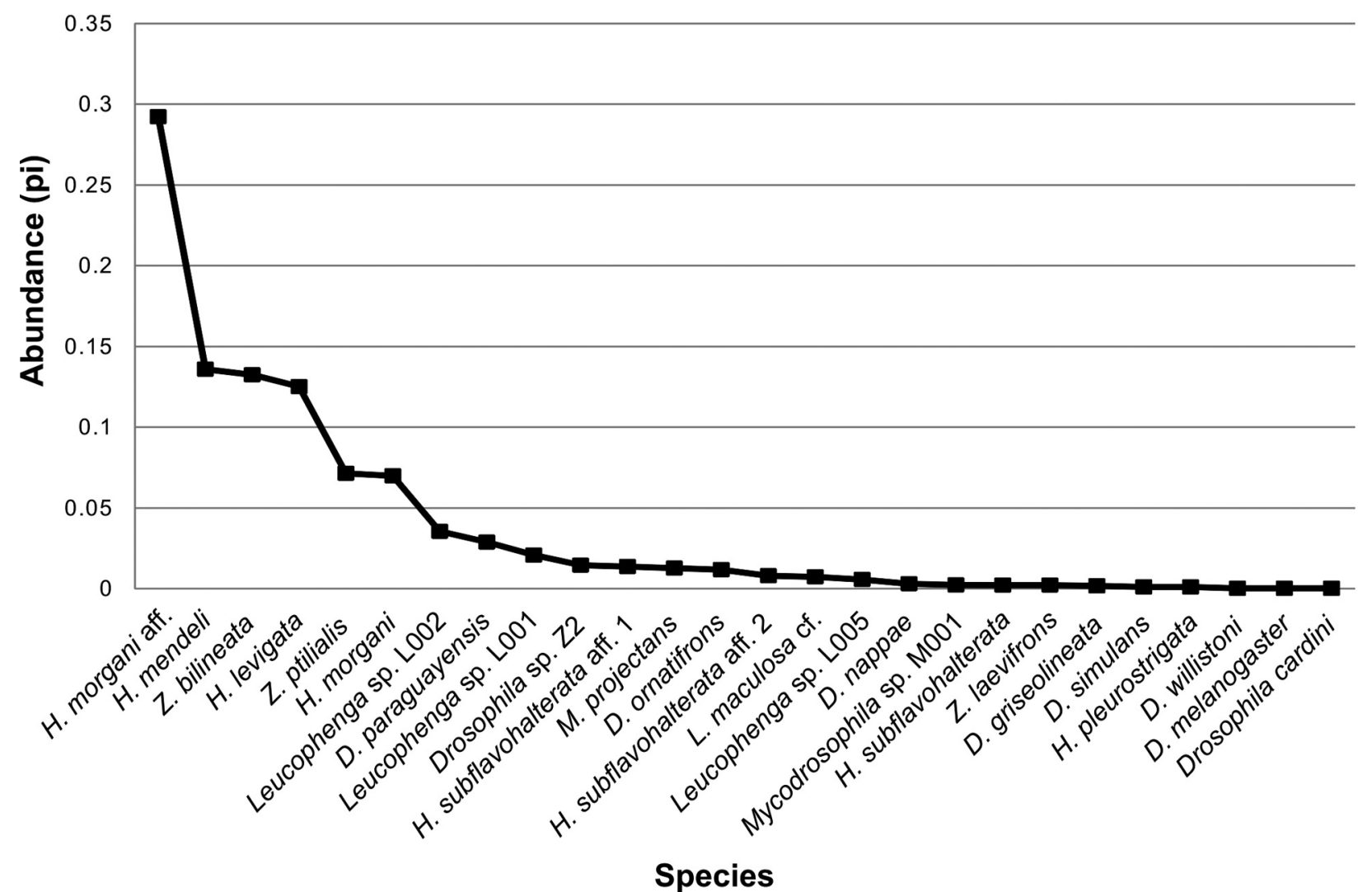

Figure 3 - Whittaker plot of relative abundance (pi) of emerged drosophilid from Basidiomycetes fungal species in Horto Botânico Irmão Teodoro Luís.

Zygothrica sp.Z002], were only collected as adult flies and did not emerge from the fruiting bodies (Table II).

With the exception of $H$. levigata and $H$. morgani aff., all of the Hirtodrosophila species emerged from two species of Auricularia: A. auricula-judae and A. polytricha. Auricularia auriculajudae was the main resource of $H$. morgani aff., the dominant species in the assemblage, although only two flies of this species emerged from Polyporus sp.1. Other species that displayed a narrow range of fungal trophic resources were L. maculosa cf. (Coquillett in Johnson) and Leucophenga sp. L005, which were sampled emerging from Agaricus sp.4 and Agaricus sp.7. Certain species were commonly sampled in banana-baited traps, such as the exotic Drosophila melanogaster Meigen and D. simulans Sturtevant, and the Neotropical species D. cardini
Sturtevant and D. willistoni cf. Sturtevant were collected emerging from a single species of fungi.

Fig. 5 shows the two first axes obtained with the CA. Axis 1 explains $15.54 \%$ of the total variation of the sample, whereas axis 2 explains $13.18 \%$. Three independent clusters of drosophild species were established and corroborated by ANOSIM ( $\mathrm{p}=0.0003$ for all comparisons): (1) four species of Hirtodrosophila (H. mendeli, $H$. morgani, $H$. morgani aff. and $H$. subflavohalterata aff. 1 were associated with $A$. auricula-judae and $A$. polytricha; (2)Leucophenga sp.L001,Leucophenga sp.L002, Leucophenga sp.L005 and Z. bilineata were associated with Agaricus sp.4, Agaricus sp.6, Agaricus sp.7, Lepiota sp.1 and Marasmius sp.7; and (3) D. ornatifrons, D. paraguayensis, $H$. levigata, M. projectans and Z. ptilialis were associated with a wider range of fungal species 
and genera, including Agaricus sp.2, Agaricus sp.6, Fomitopsis sp.1, Geastrum sp.3, Lepiota sp.1, Marasmius sp.2, Marasmius sp.4, Marasmius sp.5,
Marasmius sp.7, Pleurotus sp.2, Polyporus sp.1, Pycnoporus sp.1 and Trametes sp.2. The last group appears to be composed of more generalist species.

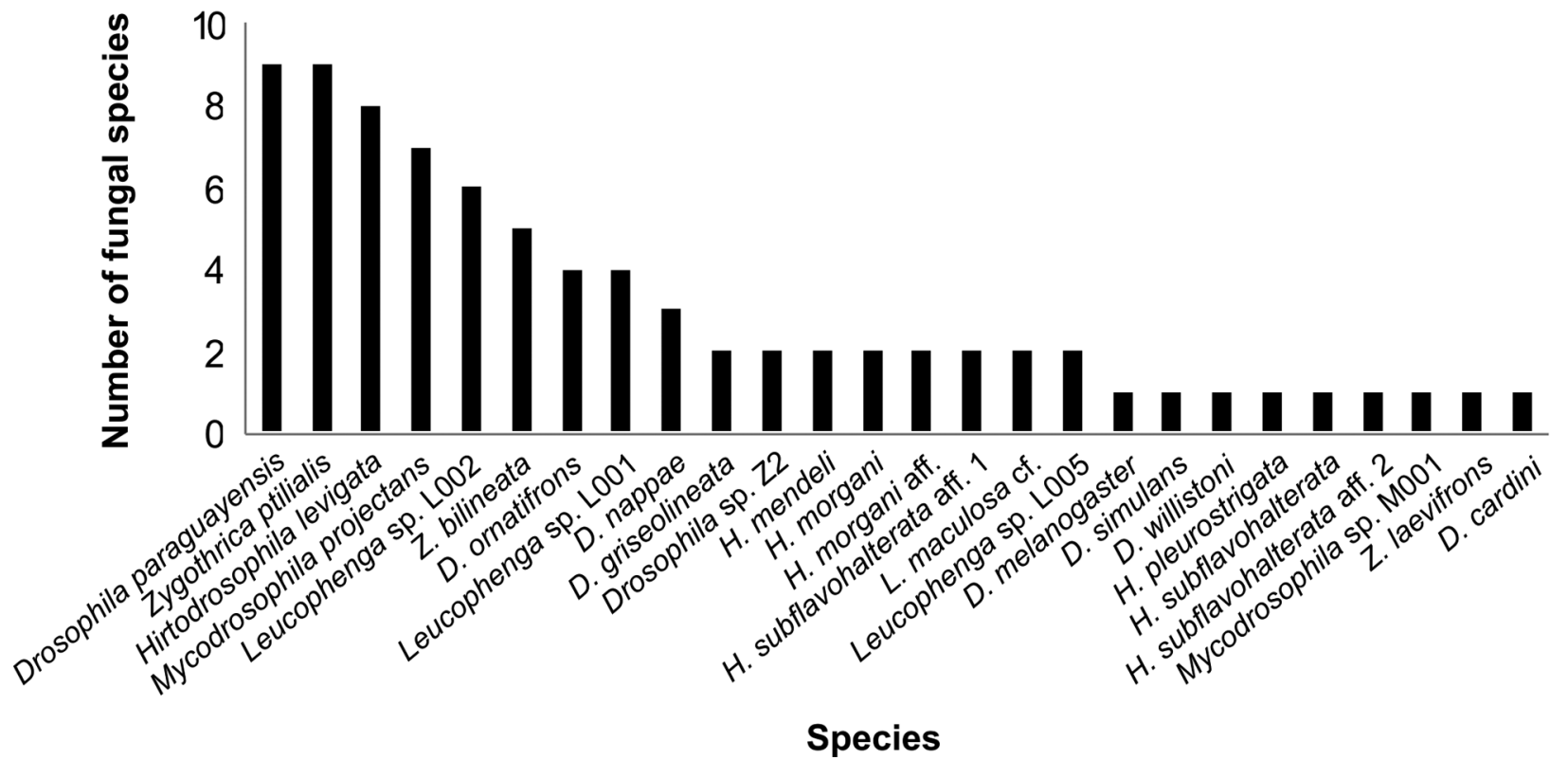

Figure 4 - Number of Basidiomycetes fungal species used by each species of drosophilid.

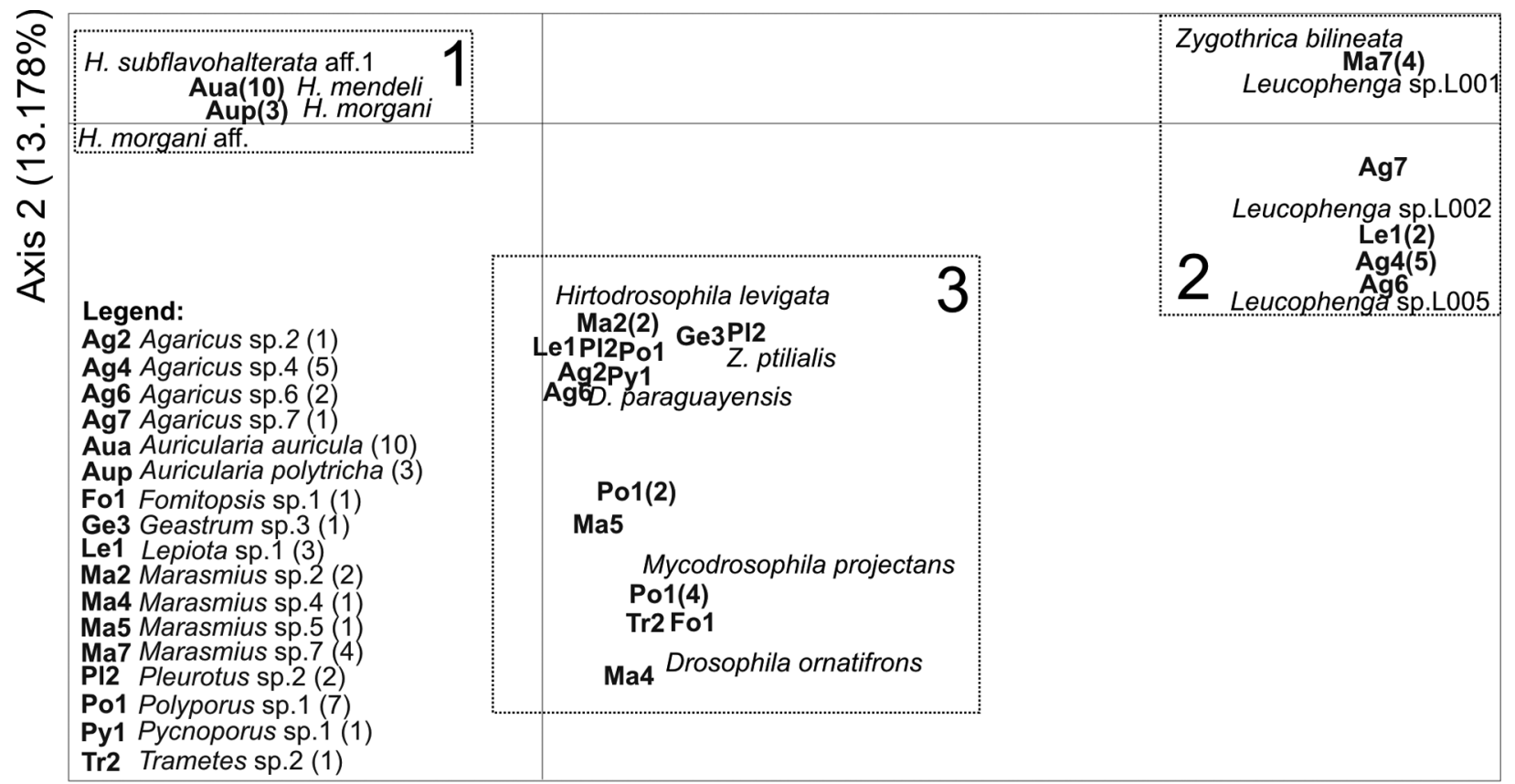

\section{Axis $1(14.538 \%)$}

Figure 5 - Axis 1 and 2 of the correspondence analysis (CA) relating the species of drosophilid and host fungal species from which they emerged. Samples of fungi are shown in bold. The number of samples used in the CA is shown in brackets in the legend. The numbered squares represent independent groups of drosophilid species according the analysis of similarity (ANOSIM). 


\section{DISCUSSION}

In this study, we provided valuable information on the diversity of Basidiomycetes resources used by drosophilid species in the Neotropical region. We provided emergence data for 26 species, including Hirtodrosophila levigata, $H$. mendeli, $H$. pleurostrigata (Burla), Zygothrica bilineata and Z. ptilialis, for which no fungal host has previously been reported (Gottschalk et al. 2009, Grimaldi 1987, Roque et al. 2006, Roque and Tidon 2008, Val and Kaneshiro 1988). Nine collected species could not be identified (Drosophila sp.Z2, H. morgani aff., $H$. subflavohalterata aff. $1, H$. subflavohalterata aff.2, Mycodrosophila sp.M001, Zygothrica sp.Z002, Leucophenga sp.L001, Leucophenga sp.L002 and Leucophenga sp.L005) and may represent undescribed species. This unexplored diversity highlights the importance of the sampled area for additional taxonomic surveys, particularly because the dominant species of the assemblage $(H$. morgani aff.) is an undescribed species.

The increased availability of fungal species (measured by number of samples and relative frequency) led to increased abundance and species richness of the associated drosophilid. Döge et al. (2015) observed that the availability of resources is the main factor affecting the size of the populations of two species of drosophilids. We observed a positive correlation between for the mass of fungal species and drosophilid abundance, although a correlation was not observed between mass of fungal species and drosophilid species richness. Apparently, the drosophilid species were restricted to ovipositing or breeding on fungal species and could only colonize a limited number of species despite the high availability.

Regarding the diversity of the assemblage, our results are consistent with previous studies that assessed the emergence of drosophilid from Basidiomycetes fungi in the Neotropics, and we showed that the most species-rich genus was Drosophila and most abundant genus was
Hirtodrosophila (Gottschalk et al. 2009, Roque et al. 2006). The dominance of Hirtodrosophila is most likely associated with the high colonization rates of Auricularia (Appendix S1) and high sample number of this fungus, which is the main trophic resource for Hirtodrosophila larvae in our study.

Drosophilids associated with fungi have been subject to extensive sampling in Japan (Toda et al. 1999), the United States (Lacy 1984) and Europe (Shorrocks and Charlesworth 1980), and these studies reported that a few species were highly dominant in relation to others, which is consistent with our results. The highest number of Drosophila species groups observed in our study belonged to the immigrans-tripunctata radiation, which is notable for its mycophagous habits (Courtney et al. 1990, Gottschalk et al. 2009, Lacy 1984, MoralesHojas and Vieira 2012). Drosophila paraguayensis, which belongs to tripunctata species group, are frequently found on fruit but was the most abundant Drosophila species in our samples, suggesting that fungi are important breeding sites for this species, especially in summer and autumn. Saavedra et al. (1995) recorded a low emergence of $D$. paraguayensis from fruit in summer and autumn, although this species was observed breeding on fruit in spring and winter. In addition, Garcia et al. (2012), Hochmüller et al. (2010) and Poppe et al. (2012) sampled D. paraguayensis and observed low abundance in summer and autumn with banana-baited traps. Most likely, this versatile species changes its larval resources (i.e., fruit and fungi) seasonally, and this behavior is supported by the results of our study because $D$. paraguayensis was sampled in nine fungal species.

Drosophila melanogaster, D. simulans and D. willistoni cf., species, which breed on fruit, were collected occasionally in low abundance on fungus. The colonization of fungi by $D$. willistoni corroborates Roque et al. (2006), who collected this species emerging from Agaricales and Boletales.

van Klinken and Walter (2001) sampled 37 species of drosophilids emerging from fungi 
belonging to Agaricales, Aphyllophorales, Auriculariales and Boletales in Australia and suggested that their niches overlap. Although certain species of Hirtodrosophila, Leucophenga, Lissocephala Malloch, Mycodrosophila, Paramycodrosophila, Scaptodrosophila Duda and Zygothrica emerged exclusively from fungi, species of Drosophila, Leucophenga and Scaptodrosophila also emerged from flowers and fruits. The trophic niche of Hirtodrosophila, Mycodrosophila and Drosophila species are similar in the Neotropical region, with the former two genera restricted to fungi (Grimaldi 1987, Heed 1957) and Drosophila using other substrates as breeding resources (Carson 1971). However, for Leucophenga species in the Neotropics, fungal fruiting bodies are the only substrate in which they are known to rear their larvae (Gottschalk et al. 2009, Heed 1957, Roque et al. 2006).

Of the species collected on fruiting bodies, a subset of Zygothrica species did not emerge, which is consistent with Grimaldi (1987), who reported the use of fungal fruiting bodies as a courtship arena for Zygothrica. However, adult Leucophenga were not collected on fruiting bodies and were only collected as they emerged. Lachaise and Tsacas (1983) suggest that the feeding and breeding sites of Leucophenga species are distinct, which could explain our results.

Data in the literature suggest that most mycophagous drosophilid species have generalist habits because fruiting bodies are considered to be nutritionally homogeneous (Courtney et al. 1990, Hanski 1989). Thus, oligophagous or specialist species would be uncommon, and records reporting such habits would most likely be artefacts of insufficient sampling effort (Hanski 1989). Our results provide evidence that is inconsistent with this hypothesis because only 9 of the 26 drosophilid species were observed colonizing three or more fungal species, most of the recorded species were collected in fewer than two fungal species, and most species of Hirtodrosophila and Leucophenga were restricted to abundant fungal species (in collected sample mass), indicating specialization for these resources. In addition, we found species of drosophilid that were closely associated with Auricularia, Agaricus, Lepiota and Melanoleuca. The emerged fauna of Auricularia were the most particular and primarily represented by species of the hirticornis group of Hirtodrosophila. Auricularia was the most frequent and abundant in HBITL, and according to Courtney et al. (1990), these features are necessary to host a specialized fauna. The generalist habit described by Courtney et al. (1990) and Hanski (1989) in the Holarctic region may be a result of the absence of specialist species of Hirtodrosophila, Leucophenga and even Zygothrica because Drosophila is the dominant genus of mycophagous drosophilid assemblages in the Holarctic.

In conclusion, the studied drosophilid assemblage was dominated by Hirtodrosophila, and Drosophila was the most species-rich genus. The dominance of Hirtodrosophila should reflect a specialist habit, whereas the higher species richness of Drosophila may reflect a generalist habit. The presence of drosophilids with specialist habits was most likely not a sampling artifact because the species richness did not increase with the mass of the fungal samples, suggesting a restriction imposed by fungal species on colonization by generalist drosophilids. The differences between the assemblage observed in our results and assemblages studied in the Holarctic region may have been caused by the lower species richness of specialized genera.

\section{ACKNOWLEDGMENTS}

We would like to thank Prof. Lizandra Jaqueline Robe, Prof. Cristiano Agra Iserhard and the anonymous reviewers for their helpful comments and improve the manuscript and Liliane Nachtigall Martins for their practical assistance in the field and fly identification. This work was supported 
by the Conselho Nacional de Desenvolvimento Científico e Tecnológico (CNPq) under grant $n^{\circ}$ 472973/2013-4 and 471174/2013-0. The collection was authorized by the Instituto Chico Mendes de Conservação da Biodiversidade (ICMBio), under permanent license for collecting biological material $n^{\circ} 25454-1$.

\section{RESUMO}

Drosophilidae é uma das mais representativas famílias de insetos presentes em corpos de frutificação de fungos Basidiomicetes; no entanto, a diversidade e a estrutura da comunidade de Drosophilidae micófagos na região Neotropical é pouco conhecida. O objetivo deste estudo foi descrever a diversidade de Drosophilidae micófagos e investigar sua colonização em fungos hospedeiros em uma mata no sul do Brasil. De 120 amostras de fungos (agrupamentos de cogumelos), de 17 gêneros de Basidiomycetes, foram registradas moscas emergentes de 70 amostras e coletadas em estágio adulto de 25 amostras de fungos, totalizando 4.897 drosofilídeos pertencentes a 31 espécies e 5 gêneros. Drosophila Fallén foi o gênero com maior riqueza, enquanto Hirtodrosophila Duda foi o gênero dominante. Estudos realizados na região Holártica sugerem que drosofilídeos micófagos apresentam hábitos generalistas; no entanto, nossos resultados mostraram que a maioria dos drosofilídeos usam menos do que dois fungos hospedeiros, e que a maioria das espécies de Hirtodrosophila e Leucophenga foram restritas às duas espécies mais abundantes de fungos, indicando uma especialização por estes recursos. A fauna mais especializada emergiu de Auricularia, o qual foi o gênero fúngico mais frequente em nossa amostragem, e este resultado corrobora a hipótese de que a especialização depende da disponibilidade dos recursos fungícos ao longo do tempo.

Palavras-chave: espécies generalistas, micofagia, cogumelos, bioma Pampa, espécies especialistas, nicho trófico.

\section{REFERENCES}

Agrometeorological Station of Pelotas. 2015. [Cited on April 20, 2015]. Available from URL: http://www. cpact.embrapa.br/agromet/estacao.

BUNYARD BA. 2003. Biodiversity and ecology of mycophagous Diptera in northeastern Ohio. P Entomol Soc Wash 105: 847-858.
BURLA H. 1956. Die Drosophilidengattung Zygothrica und ihre beziehung zur Drosophila-untergattung Hirtodrosophila. Mitt Zool Mus Berl 2: 189-321.

CARSON HL. 1971. The ecology of Drosophila breeding sites. Harold L. Lyon Arboretum Lecture, n. 2. Honolulu: The University of Hawaii Press, 28 p.

COLWELl RK. 2006. EstimateS ver. 8.2.0: Statistical estimation of species richness and shared species from samples. Available from: http://purl.oclc.org/estimates.

CORDEIRO AR. 1952. Drosophila (Hirtodrosophila) caxiensis, a new species of fungus-feeding fly from Brasil. Dusenia 3: 303-308.

COURTNEY SP, KiBOTA TT AND SINGLETON TA. 1990. Ecology of mushroom-feeding Drosophilidae. In: Begon B, Fitter AH and Macfadyen A (Eds), Advances in Ecological Research, London: Academic Press, p. 225-274.

DÖGE JS, DE OLIVEIRA HV AND TIDON R. 2015. Rapid response to abiotic and biotic factors controls population growth of two invasive drosophilids (Diptera) in the Brazilian Savanna. Biol Invasions 17: 2461-2474.

EPPS MJ AND ARNOLD AE. 2010. Diversity, abundance and community network structure in sporocarp-associated beetle communities of the central Appalachian Mountains. Mycologia 102: 785-802.

FROTA-PESSOA O. 1945. Sobre o subgênero Hirtodrosophila, com descrição de uma nova espécie(Diptera, Drosophilidae, Drosophila). Rev Bras Entomol 5: 469-483.

Frota-PessoA O. 1951. Drosophila (Hirtodrosophila) magnarcus n. sp. (Diptera, Drosophilidae). Rev Bras Entomol 11: 407-411.

GARCia CF, Hochmüller CJC, VALEnte VLS AND SCHMITZ HJ. 2012. Drosophilid assemblages at different urbanization levels in the city of Porto Alegre, state of Rio Grande do Sul, Southern Brazil. Neotrop Entomol 41: 3241.

Gottschalk MS, Bizzo LEM, DöGe JS, Profes MS, HOFMANN PRP AND VALENTE VLS. 2009. Drosophilidae (Diptera) associated to fungi: differential use of resources in anthropic and Atlantic Rain Forest areas. Iheringia Ser Zool 99: 442-448.

GRIMALDI D. 1987. Phylogenetics and taxonomy of Zygothrica (Diptera: Drosophilidae). B Am Mus Nat Hist 186: 103-268.

GRIMALDI D. 1990. A phylogenetic, revised classification of the genera in the Drosophilidae (Diptera). B Am Mus Nat Hist 197: 1-139.

HAMMER Ø, HARPER DAT AND RYAN PD. 2001. PAST: Paleontological statistics software package for education and data analysis. Palaeontol Electron 4: 1-9.

HANSKI I. 1989. Fungivory: fungi, insects and ecology. In: Wilding N, Collins NM, Hammond PM and Webber JB (Eds), Insect-fungus interaction. London: Academic Press, p. 25-68. 
HEED WB. 1957. Ecological and distributional notes on the Drosophilidae (Diptera) of El Salvador. In: Wheeler MR (Ed), Studies in the Genetics of Drosophila, Texas: University of Texas Publication, p. 62-78.

HOCHMÜLLER CJC, LOPES-DA-SILVA M, VALENTE VLS AND SCHMITZ HJ. 2010. The drosophilid fauna (Diptera, Drosophilidae) of the transition between the Pampa and Atlantic Forest Biomes in the state of Rio Grande do Sul, southern Brazil: first records. Pap Avulsos Zool 50: 285295.

KANESHIRO K. 1969. A study of the relationships of Hawaiian Drosophila species based on the external male genitalia. The University of Texas Publication 6918: 55-69.

KotTeK M, GRIESER J, BecK C, RUdolf B AND RUBEL F. 2006. World Map of the Köppen-Geiger climate classification updated. Meteorol Z 15: 259-263.

KreBS C. 1999. Ecological Metodology. San Francisco: Benjamin Cummings, $624 \mathrm{p}$.

LACHAISE D AND TSACAS L. 1983. Breeding-sites in tropical African drosophilids. In: Ashburner M, Carson HL and Thompson Jr JN (Eds), The Genetics and Biology of Drosophila, London: Academic Press, p. 221-332.

LACY R. 1984. Predictability, toxicity, and trophic niche breadth in fungus-feeding Drosophilidae (Diptera). Ecol Entomol 9: 43-54.

LAESSOE T AND LiNCOFF G. 2010. Mushrooms. The clearest recognition guides available. London: Dorling Kindersley, $304 \mathrm{p}$.

LINCOFF G. 1981. Simon and Schuster's guide to mushrooms. New York: A Fireside Book, 511 p.

LINCOFF G. 2010. The complete mushroom hunter: an illustrated guide to finding, harvesting and enjoying wild mushrooms. Beverly: Quarry Books, 192 p.

MARKOW TA AND O'GRADY PM. 2006. Drosophila: A guide to species identification and use. London: Academic Press, $259 \mathrm{p}$.

MARKOW TA AND O'GRADY PM. 2008. Reproductive ecology of Drosophila. Funct Ecol 22: 747-759.

MORAleS-HOJAS R AND VieIRA J. 2012. Phylogenetic patterns of geographical and ecological diversification in the subgenus Drosophila. PLoS ONE 7: 1-15.

MOURÃO CA, GALlO AJ AND BICUdO HEMC. 1965. Sobre a sistemática de Drosophila no Brasil, com descrição de $D$. mendeli sp.n. e "Relação de espécies brasileiras do gênero Drosophila". Cienc Cult 17: 577-586.

POLESE JM. 2005. The pocket guide to mushrooms. Slovakia: Könemann, $381 \mathrm{p}$.

POPPE JL, VALENTE VLS AND SCHMITZ HJ. 2012. Structure of Drosophilidae assemblage (Insecta, Diptera) in Pampa Biome (São Luiz Gonzaga, RS). Pap Avulsos Zool 52: 185-195.

PutzKe J AND PutzKe MTL. 1998. O Reino dos Fungos. Santa Cruz do Sul: EDUNISC, 606 p.
REMSEN J AND O'GRADY P. 2002. Phylogeny of Drosophilinae (Diptera: Drosophilidae), with comments on combined analysis and character support. Mol Phylogenet Evol 24: 249-264.

RoQue F, FigueIREDO R AND TIDON R. 2006. Nine new records of drosophilids in the Brazilian savanna. Drosoph Inf Serv 89: 14-17.

ROQUE F AND TIDON R. 2008. Eight new records of drosophilids (Insecta; Diptera) in the Brazilian savanna. Drosoph Inf Serv 91: 94-98.

SAAVEDRA CCR, CALLEGARI-JACQUES SM, NAPP M AND VALENTE VLS. 1995. A descriptive and analytical study of four Neotropical drosophilid communities. J Zool Syst Evol 33: 62-74.

SHORROCKS B AND CHARLESWORTH P. 1980. The distribution and abundances of the British fungal-feeding Drosophila. Ecol Entomol 5: 61-78.

SMITH EP AND VAN BELLE G. 1984. Nonparametric estimation of species richness. Biometrics 40: 119-129.

TAKAHASHI KH, TUNO N AND KAGAYA T. 2005. The relative importance of spatial aggregation and resource partitioning on the coexistence of mycophagous insects. Oikos 109: 125-134.

THROCKMORTON LH. 1975. The phylogeny, ecology and geography of Drosophila. In: King RC (Ed), Handbook of Genetics, New York: Plenum Press, p. 421-469.

TODA MJ, Kimura MT AND TUNO N. 1999. Coexistence mechanisms of mycophagous drosophilids on multispecies fungal hosts: aggregation and resource partitioning. J Anim Ecol 68: 794-803.

TUNO N. 1999. Insect feeding on spores of a bracket fungus, Elfvingia applanata (Pers.) Karst. (Ganodermataceae, Aphyllophorales). Ecol Res 14: 97-103.

VAL FC AND KANESHIRO KY. 1988. Drosophilidae (Diptera) from the Estação Biológica de Boracéia, on the coastal range of the state of São Paulo, Brazil: geographical distribution. In: Vanzolini PE and Heyer WR (Eds), Proceedings of a Workshop on Neotropical Distribution Patterns, Rio de Janeiro: Acad Bras Cienc, p. 189-203.

VAN KLINKEN RD AND WALTER GH. 2001. Larval hosts of Australia Drosophilidae (Diptera): A field survey in subtropical and tropical Australia. Aust J Entomol 40: 163-179.

VILELA CR AND BÄCHLI G. 1990. Taxonomic studies on Neotropical species of seven genera of Drosophilidae (Diptera). Mitt Schweiz Entomol Ges 63(Suppl.): 1-332.

VILELA CR AND BÄCHLI G. 2004. On the identities of nine Neotropical species of Hirtodrosophila (Diptera, Drosophilidae). Mitt Schweiz Entomol Ges 77: 161-195.

VILELA CR AND BÄCHLI G. 2007. Revision of the Neotropical genus Paraliodrosophila (Diptera, Drosophilidae). Mitt Schweiz Entomol Ges 80: 291-317.

WERTHEIM B, SEVENSTER JG, EIJS IEM AND VAN ALPHEN JJM. 2000. Species diversity in a mycophagous insect 
community: the case of spatial aggregation vs. resource partitioning. J Anim Ecol 69: 335-351.

WHEELER MR AND KAMBYSELLIS MP. 1966. Notes on the Drosophilidae (Diptera) of Samoa. The University of Texas Publication 6615: 533-565.

WHEELER MR AND TAKADA H. 1971. Male genitalia of some representative genera of American Drosophilidae. The University of Texas Publication 7103: 225-240.

WOLFF LF, GOMES GC, RODRIGUES WF, BARBIERI RL, Medeiros CAB AND CARdoso JH. 2008. Flora apícola arbórea nativa na região serrana de Pelotas para a apicultura sustentável na Metade Sul do Rio Grande do Sul, Documentos n. 242. Pelotas: Embrapa Clima Temperado, 37 p. Available from URL: https://www. embrapa.br/busca-de-publicacoes/-/publicacao/746892/ flora-apicola-arborea-nativa-na-regiao-serrana-depelotas-para-a-apicultura-sustentavel-na-metade-sul-dorio-grande-do-sul.

\section{SUPPLEMENTARY MATERIAL}

Appendix S1 (Supporting Information) - Basidiomycetes samples that were positive (gray) and negative (black) for the emergence of Drosophilidae. The numbers under the charts represent the total number of samples collected from each Basidiomycetes genus. 